\title{
BP Neural Network Improved by Sparrow Search Algorithm in Predicting Debonding Strain of FRP-Strengthened RC Beams
}

\author{
Guibing Li $\mathbb{D}^{1}{ }^{1}$ Tianyu Hu $\mathbb{D D}^{1}{ }^{1}$ and Dawei Bai ${ }^{2}$ \\ ${ }^{1}$ School of Management Science and Engineering, Shandong Technology and Business University, Yantai 264005, \\ Shandong, China \\ ${ }^{2}$ School of Civil Engineering and Transportation, Hohai University, Nanjing 210024, Jiangsu, China \\ Correspondence should be addressed to Guibing Li; leegb@sina.com
}

Received 15 March 2021; Accepted 18 May 2021; Published 28 May 2021

Academic Editor: Faming Huang

Copyright (C) 2021 Guibing Li et al. This is an open access article distributed under the Creative Commons Attribution License, which permits unrestricted use, distribution, and reproduction in any medium, provided the original work is properly cited.

To prevent debonding failure of FRP- (fiber reinforced polymer-) strengthened RC (reinforced concrete) beams, most codes proposed models for debonding strain limitation of FRP reinforcements. However, only a few factors that affect debonding failure are considered in the models. The experimental results show that these models cannot accurately evaluate debonding strain and have a large variability. In order to improve the accuracy of predicting the debonding strain of FRP-strengthened RC beams, a BP neural network model was developed based on the sparrow search algorithm (SSA). To predict the debonding strain of FRP reinforcements, the established neural network model was trained and simulated through experimental data. The results show that the coefficient of variation of the present SSA-BP neural network model is $13 \%$. The main factors affecting debonding strain are the longitudinal reinforcement ratio, stirrup reinforcement ratio, and concrete strength, which are not considered in the code models. The present model has better prediction accuracy and more robustness than the traditional BP neural network and the code models.

\section{Introduction}

In the past decades, FRP (fiber reinforced polymer) reinforcements have been widely used in the rehabilitation and strengthening of existing reinforced concrete (RC) structures due to their lightweight, high strength, and good corrosion resistance [1]. Many researchers have conducted experimental and numerical studies on the flexural performance of FRP-strengthened RC beams [2-6]. Intermediate crack-induced debonding failure is the dominant failure mode of FRP-strengthened RC beams. Most of the codes have proposed different models of debonding strain limitation for prevention of debonding failure [7-10]. ACI440.2R [7] corrected the model of Teng [11] based on the maximum tensile strain of the FRP-strengthened RC beams with intermediate crack-induced debonding failure and proposed a model to limit the debonding strain of FRP reinforcements. Kim and Harries [12] proposed a statistical model of FRP effective strain based on the Monte Carlo method. Oller et al. [13] established the model of FRPconcrete interface ultimate tensile based on nonlinear fracture mechanics and the bilinear constitutive relationship of the FRP-concrete interface. Lu et al. [14] proposed a model of FRP ultimate tensile strain based on the shear test and finite element analysis. Bilotta et al. [15] established the standard value and design value calculation model of the maximum tensile strain of FRP reinforcements. However, the experimental results and statistical analysis $[13,16-18]$ show that these models cannot evaluate debonding strain accurately and have a large coefficient of variation as only a few factors that affect the debonding strain are considered in these models.

In the recent decades, the BP neural network has been applied in various fields of civil engineering, including the assessment of compressive strength of ultrahigh-performance concrete [19], the study of material intrinsic model [20], and prediction of shear strength and behavior of RC beams strengthened with externally bonded FRP sheets [21], 
but the research on the debonding strain of FRPstrengthened RC beams is still relatively rare [22]. Since many factors are affecting the debonding failure, such as the mechanical properties of materials, the geometry of the member, deformation and cracks of the specimen, etc., and there are complex nonlinear relationships between the debonding strain and each parameter, the calculation formulas established based on theoretical and experimental results usually have low accuracy and large variability, which cannot prevent the debonding failure of FRP-strengthened beams. The BP neural network has the characteristics of nonlinear mapping theoretically and can provide a better simulation of complex nonlinear relationships. However, in the determination of weights and thresholds using the gradient descent method, the BP neural network is easy to lead the model into the local optimum and make convergence speed slow; it needs to be improved by a better algorithm [23]. This paper introduced the sparrow search algorithm (SSA) to optimize the weights and thresholds of the network [24] and the nonlinear mapping relationship between each parameter and the debonding strains of FRPstrengthened RC beams.

\section{BP Neural Network and Sparrow Search Algorithm}

2.1. BP Neural Network. BP (backpropagation) neural network is a multilayer forward neural network trained according to the error backpropagation algorithm, including the input layer, hidden layer, and output layer. It uses gradient descent to adjust the weights and thresholds for each layer of the neuron to reduce errors in the network output until the errors reach a given error convergence level before training the network. The BP neural network can perform arbitrary nonlinear mapping of input and output and realize self-learning and simple structure, but the disadvantage of the BP neural network is that it is easy to drop to a local minimum and has poor stability [22-24]. The basic structure of the BP neural network is shown in Figure 1. follows:

The rules for the collection of experimental data are as

2.2. Sparrow Search Algorithm. The sparrow search algorithm (SSA) is a novel swarm intelligence optimization algorithm proposed in 2020, mainly inspired by the foraging and antipredatory behavior of sparrows $[25,26]$.

In the sparrow search algorithm, the priority to obtain food is the sparrow with a higher fitness value. Besides, the sparrow as a discoverer searches for a target for the whole population and directs the joiners to search for food (target), i.e., the sparrow as a discoverer has a larger search range compared with the joiners. As the iteration proceeds, the location of the sparrow as a discoverer is described in the following equation:

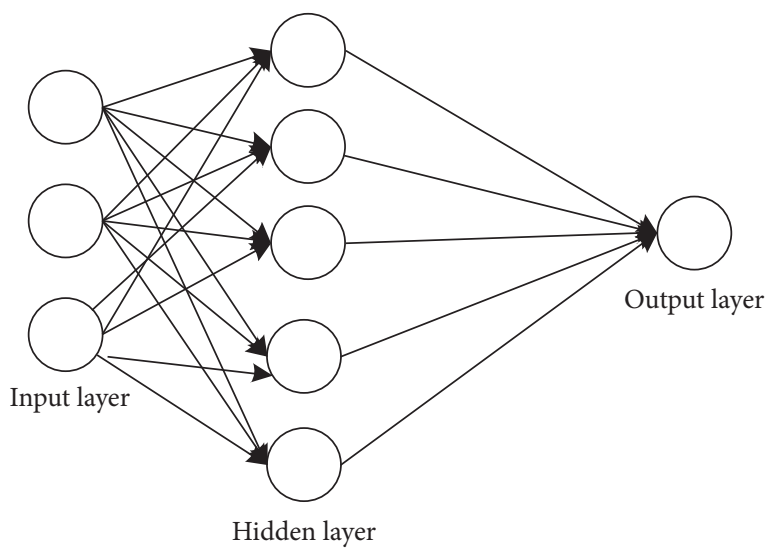

FIgURE 1: Structure diagram of neural network.

$$
X_{i, j}^{t+1}= \begin{cases}X_{i, j}^{t} \cdot \exp \left(\frac{-i}{\alpha \cdot \text { iter }_{\text {max }}}\right), & \text { if } R 2<S T, \\ X_{i, j}^{t}+Q \cdot L, & \text { if } R 2 \geq S T,\end{cases}
$$

where $t$ is the current number of iterations and iter max $_{\text {ma }}$ is constant representing the maximum number of iterations. $X_{i, j}$ is the position information of the $i$-th sparrow in the $j$-th dimension. $\alpha \in(0,1]$ is a random number. $R_{2}\left(R_{2} \in[0,1]\right)$ and ST $(S T \in[0.5,1])$ represent the warning value and safety value, respectively. $Q$ is a random number that obeys the normal distribution. $L$ is a $1 \times d$ matrix; each element in the matrix is 1. When $R_{2}<S T$, it means that there are no predators around the foraging environment at this time, and the discoverer can perform extensive search operations. When $R_{2} \geq S T$, it means that some sparrows in the population have found a predator and have issued an alarm to other sparrows in the population. At this time, all sparrows need to fly to other safe places quickly for food.

The update of the joiner's position is shown in the following equation:

$$
X_{i, j}^{t+1}= \begin{cases}Q \cdot \exp \left(\frac{X_{\text {worst }}^{t}-X_{i, j}^{t}}{i^{2}}\right), & \text { if } i>n / 2, \\ X_{P}^{t+1}+\left|X_{i, j}^{t}-X_{P}^{t+1}\right| \cdot A^{+} \cdot L, & \text { otherwise, }\end{cases}
$$

where $X_{p}$ is the best position currently occupied by the discoverer while $X_{\text {worst }}$ is the current worst position globally. $A$ is a $1 \times d$ matrix, where each element is randomly assigned a value of 1 or -1 , and $A^{+}=A T(A A T)-1$. When $i>n / 2$, this indicates that the $i$-th joiner with a lower fitness value has no food and is in a very hungry state. At this time, it needs to fly to other places to find food to obtain more energy.

When it is aware of the danger, the sparrow population will make antipredation behavior. The mathematical expression is shown in the following equation: 


$$
X_{i, j}^{t+1}= \begin{cases}X_{\text {best }}^{t}+\beta \cdot\left|X_{i, j}^{t}-X_{\text {best }}^{t}\right|, & \text { if } f_{i}>f_{g}, \\ X_{i, j}^{t}+K \cdot\left(\frac{X_{i, j}^{t}-X_{\text {worst }}^{t}}{\left(f_{i}-f_{w}\right)+\varepsilon}\right), & \text { if } f_{i}=f_{g},\end{cases}
$$

where $X_{\text {best }}$ is the current global optimal position. As the step control parameter, $\beta$ is a random number that obeys the normal distribution with a mean value of 0 and a variance of 1. $K \in[-1,1]$ is a random number; $f_{i}$ is the fitness value of the current individual sparrow; and $f_{g}$ and $f_{w}$ are the current global best and worst fitness values, respectively. $\varepsilon$ is the smallest constant to avoid zero in the denominator.

For the sake of simplicity, when $f_{i}>f_{g}$, it means that the sparrow is at the edge of the population and is extremely vulnerable to predators. When $f_{i}=f_{g}$, this indicates that the sparrows in the middle of the population are aware of the danger and need to be close to other sparrows to minimize their risk of predation. $K$ is the direction in which the sparrow moves and is also a parameter to control the step length.

The flow chart of the BP neural network optimized by SSA is shown in Figure 2.

\section{Determination of Parameters and Collection of Experimental Data}

3.1. Determination of Parameters. The FRP-strengthened RC beams mainly consist of FRP sheets, concrete, and steel bars. According to codes and related experimental studies [8-18, 27], the parameters affecting the debonding strain are concrete strength $\left(f_{c}\right)$, FRP stiffness $\left(E_{f} t_{f}\right)$, the ratio of FRP to the length of the strengthened beam $\left(L_{f} / L\right)$, the ratio of FRP to the width of the strengthened beam $\left(b_{f} / b\right)$, the ratio of shear span to the depth of the strengthened beam $(\lambda)$, longitudinal reinforcement ratio $\left(\rho_{s}\right)$, stirrup reinforcement ratio $\left(\rho_{v}\right)$, and yield strain of steel bars $\left(\varepsilon_{s y}\right)$.

3.2. Collection of Experimental Data. In order to study the debonding strain of FRP-strengthened RC beams and train the neural network better, this study has collected $60 \mathrm{ex}-$ perimental data from different literatures. The literatures are shown in Table 1.

(1) The failure mode of the strengthened beams is intermediate crack-induced debonding

(2) The strengthened beams are under four-point loading

(3) The end of the FRP is not anchored, and there is no preload before bonding FRP

(4) The geometric characteristics of the strengthened beams and FRP reinforcements are determined

(5) The material properties of the test beam and FRP are determined

(6) The FRP bonding on the soffit of the RC beam is continuous

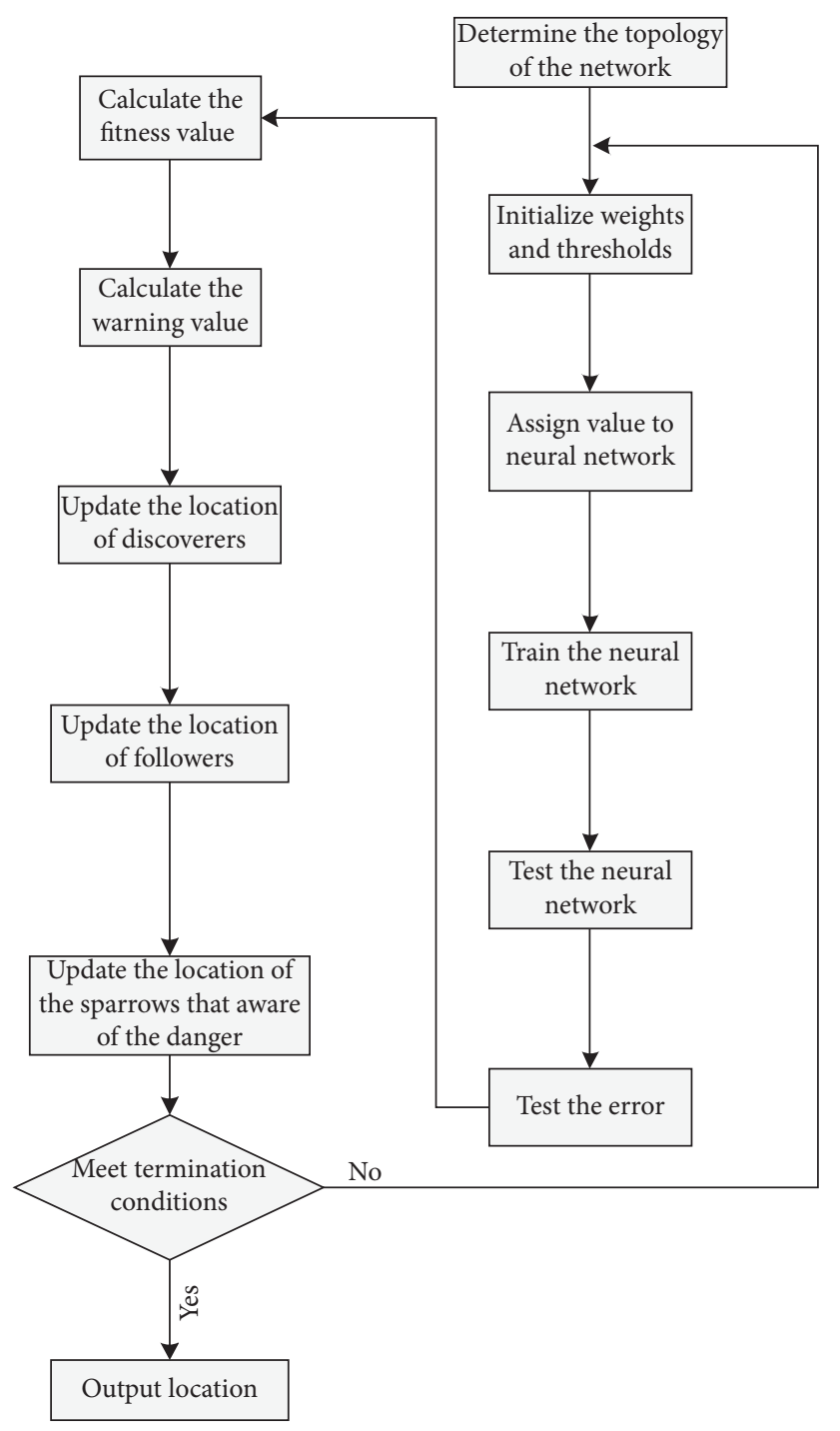

FIGURE 2: Flow chart of SSA-BP.

TABLE 1: Sources of the data.

\begin{tabular}{lc}
\hline Reference & Number \\
\hline$[28]$ & 10 \\
{$[29]$} & 6 \\
{$[30]$} & 1 \\
{$[31]$} & 1 \\
{$[32]$} & 3 \\
{$[33]$} & 2 \\
{$[34]$} & 4 \\
{$[35]$} & 2 \\
{$[16]$} & 2 \\
{$[36]$} & 2 \\
{$[37]$} & 9 \\
{$[38]$} & 4 \\
{$[39]$} & 4 \\
{$[40]$} & 1 \\
{$[41]$} & 3 \\
{$[42]$} & 6 \\
\hline
\end{tabular}


The detailed proportion of each parameter is shown in Figure 3.

From Figure 3, the following information can be found:

(1) The concrete strength $\left(f_{c}\right)$ is distributed in the range of $10-70 \mathrm{MPa}$; most of them are $40-50 \mathrm{MPa}$. The proportion of concrete strength greater than $40 \mathrm{MPa}$ is $73 \%$.

(2) The FRP stiffness $\left(E_{f} t_{f}\right)$ is between 40 and $210 \mathrm{kN} /$ $\mathrm{mm}$; the distribution of each interval is relatively uniform. The largest segment interval is $150-200 \mathrm{kN} /$ $\mathrm{mm}$ that accounts for about $33 \%$.

(3) The ratio of FRP to the length of the strengthened beam $\left(L_{f} / L\right)$ is between 0.4 and 1.0; most of them are in the range of $0.8-0.9$, which accounts for about $70 \%$. This indicates that in most tests, the length of the FRP sheet is close to the length of the beam.

(4) The ratio of FRP to the width of the strengthened beam width $\left(b_{f} / b\right)$ is between 0.1 and 0.9 . There are about $63 \%$ of all the beams with ratios greater than 0.7. Most of the sheet width is close to the width of the beam.

(5) The interval of the ratio of shear span to depth $(\lambda)$ is $2-5$. The ratios are greater than 4 , which accounts for $78 \%$, which indicates that most of the test beams have large spans.

(6) The longitudinal reinforcement ratio $\left(\rho_{s}\right)$ is between $0.3 \%$ and $1.8 \%$; the distribution in each interval is relatively even.

(7) The stirrup reinforcement ratio $\left(\rho_{v}\right)$ is between $0.1 \%$ and $1.6 \%$; the distribution in each interval is relatively even.

(8) The yield strains of steel bars $\left(\varepsilon_{s y}\right)$ are between $0.0016 \%$ and 0.0032 ; the strains are $0.0024-0.0028$ accounting for $84 \%$.

\section{Model Design and Simulation}

4.1. Design of the Model. Considering the parameters affecting the debonding strain of FRP-strengthened RC beams and the characteristics of neural networks, the design of the model of debonding strain of FRP-strengthened RC beams is as follows:

(i) Firstly, the concrete strength $\left(f_{c}\right)$, FRP stiffness $\left(E_{f} t_{f}\right)$, the ratio of FRP to the length of the strengthened beam $\left(L_{f} / L\right)$, the ratio of FRP to the width of the strengthened beam $\left(b_{f} / b\right)$, the ratio of shear span to depth $(\lambda)$, longitudinal reinforcement ratio $\left(\rho_{s}\right)$, stirrup reinforcement ratio $\left(\rho_{v}\right)$, and the yield strain of steel bars $\left(\varepsilon_{s y}\right)$ are taken as the input layer of the neural network, and the hidden layer is selected as one layer. The number of neurons in the hidden layer is determined through trials according to the empirical formula. The empirical formula is shown in the following equation:

$$
L=\sqrt{m+n}+a,
$$

where $L$ is the number of neurons in the hidden layer; $m$ is the number of neurons in the input layer; $n$ is the number of neurons in the output layer; $a$ takes an integer between 1 and 10. Considering the over- and underfitting problems, $L$ is taken as 10 after repeated debugging.

(ii) Secondly, the debonding strain is taken as the output layer. The topology of the SSA-BP model is shown in Figure 4.

4.2. Model Training and Simulation. The number of samples is 60. The distributions of the training set, validation set, and testing set are freely controlled by the neural network. The results of the SSA-BP neural network and BP neural network are shown in Figures 5-8.

It can be seen from Figures 5 and 6, the SSA-BP model has a higher regression coefficient than BP in the training and testing sets. Also, the overall regression coefficient of the SSA-BP is greater than 0.96, indicating that the present model has high accuracy. Besides, it can be seen from Figures 7 and 8 that the best root-mean-square error of the SSA-BP is 0.0061269 that is greatly lower than that of the BP (0.014484). However, the SSA-BP needs eight iterations to achieve convergence, and the BP only needs six times. This indicates that the SSA-BP needs to be improved in terms of the rate of convergence. To further compare the robustness of SSA-BP and BP, the models were trained and simulated twenty times, and the error comparison is shown in Figure 9.

It can be seen from Figure 9 that the coefficient of variation of SSA-BP is between $13 \%$ and $25 \%$, and the coefficient of variation of BP is between $15 \%$ and $45 \%$. This indicates that compared with the traditional BP neural network, the neural network optimized by SSA does not only have a relatively small error but also has stronger robustness.

4.3. Correlation Analysis of Parameters. The influence of each parameter on debonding strain is derived by the connection weights between neurons in each layer, where the input layer neurons are represented by $X_{1} \sim X_{8}$; implied layer neurons are represented by $H_{1} \sim H_{10}$; and output layer neurons are represented by $Y$. The connection weights of interlayer neurons are shown in Tables 2 and 3, and the degree of influence of $X_{1} \sim X_{8}$ on $Y$ is calculated in Equation (2), and the calculation results are shown in Figure 10:

$$
P_{x}=\sum_{i=1}^{10} w_{x i} \times h_{i} \text {, }
$$

where $P_{x}$ is the degree of influence of the parameter of the $X$ th on the debonding strain; $w_{x i}$ is the connection weight between $X$-th parameter and the $i$-th implied layer; and $h_{i}$ is the connection weight between the $i$ implied layer and the output layer, respectively. 

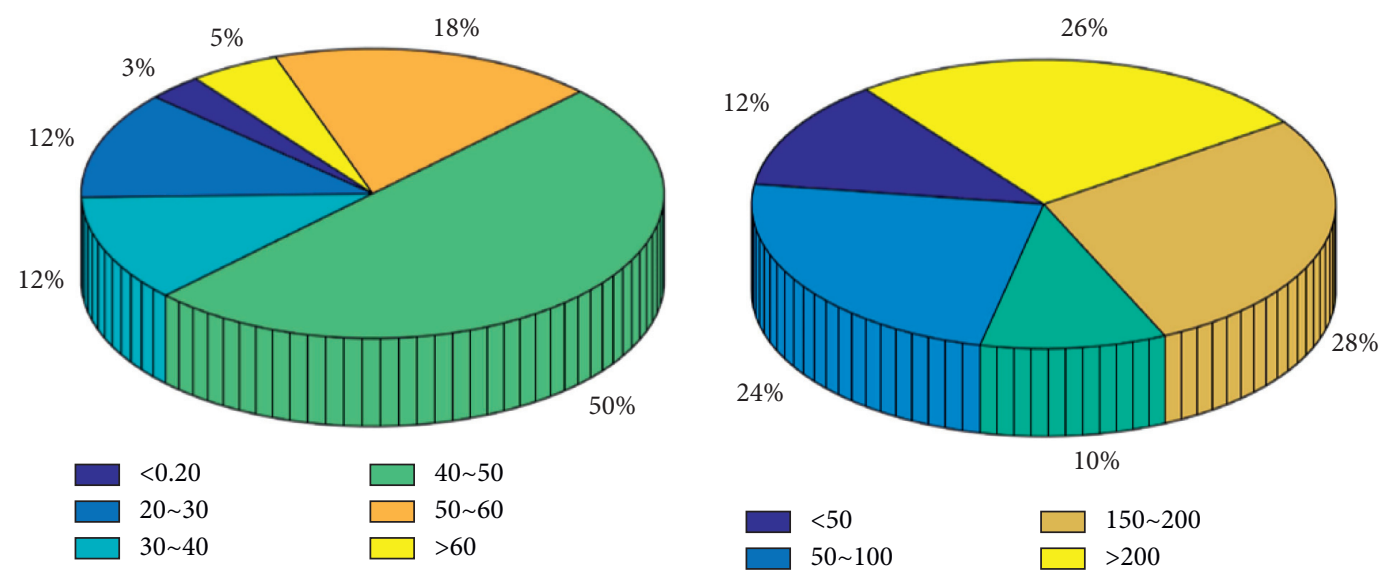

(a)

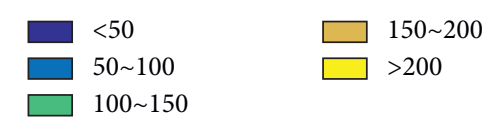

(b)
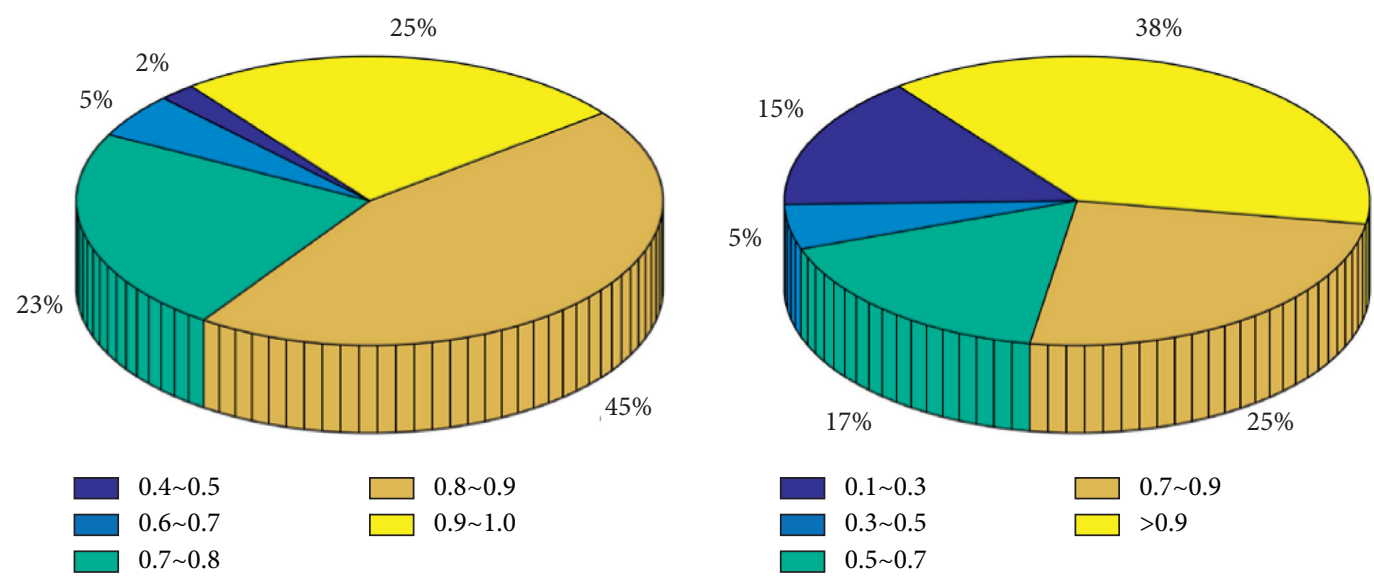

(c)

(d)
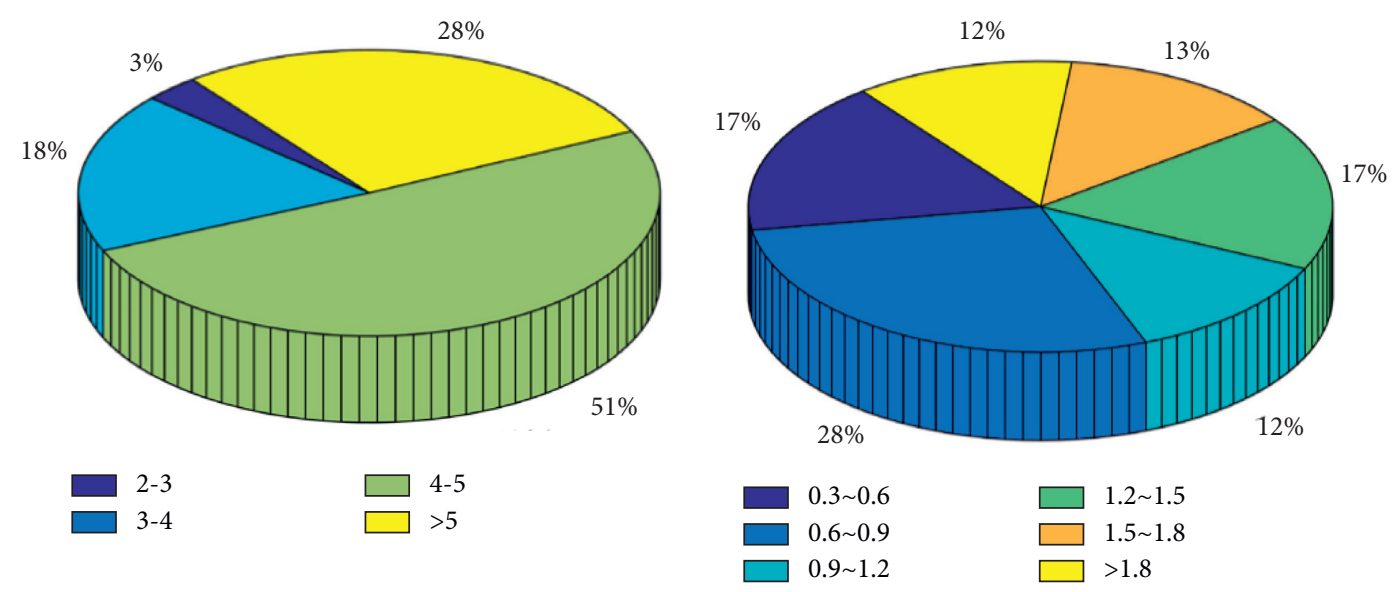

(e)

(f)

Figure 3: Continued. 


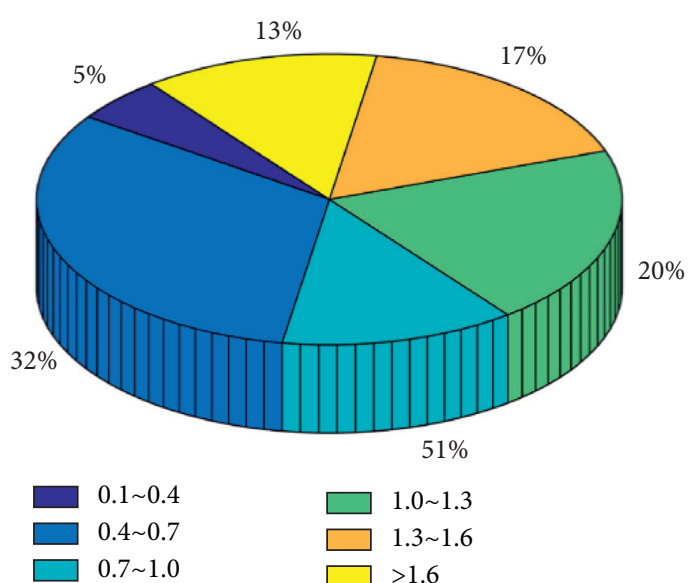

(g)
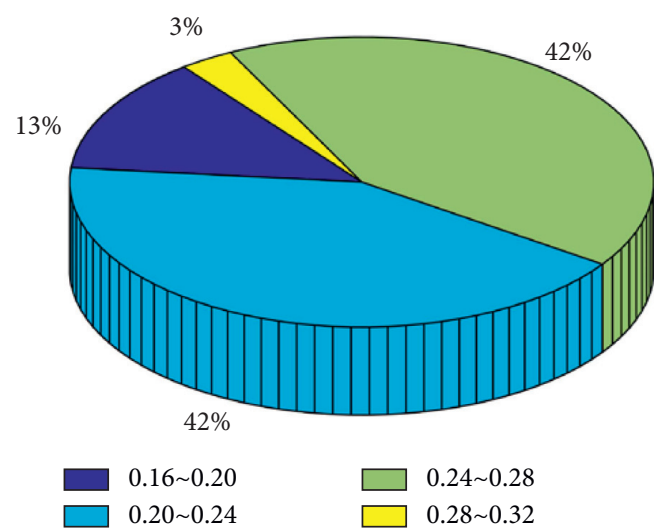

(h)

FIGURE 3: Distribution of each parameter: (a) the distribution of concrete strength, (b) the distribution of FRP stiffness, (c) the ratio of sheet length to beam length, (d) the ratio of sheet width to beam width, (e) the shear-to-span ratio, (f) longitudinal reinforcement ratio, (g) stirrup reinforcement ratio, and $(\mathrm{h})$ the yield strain of steel bars.

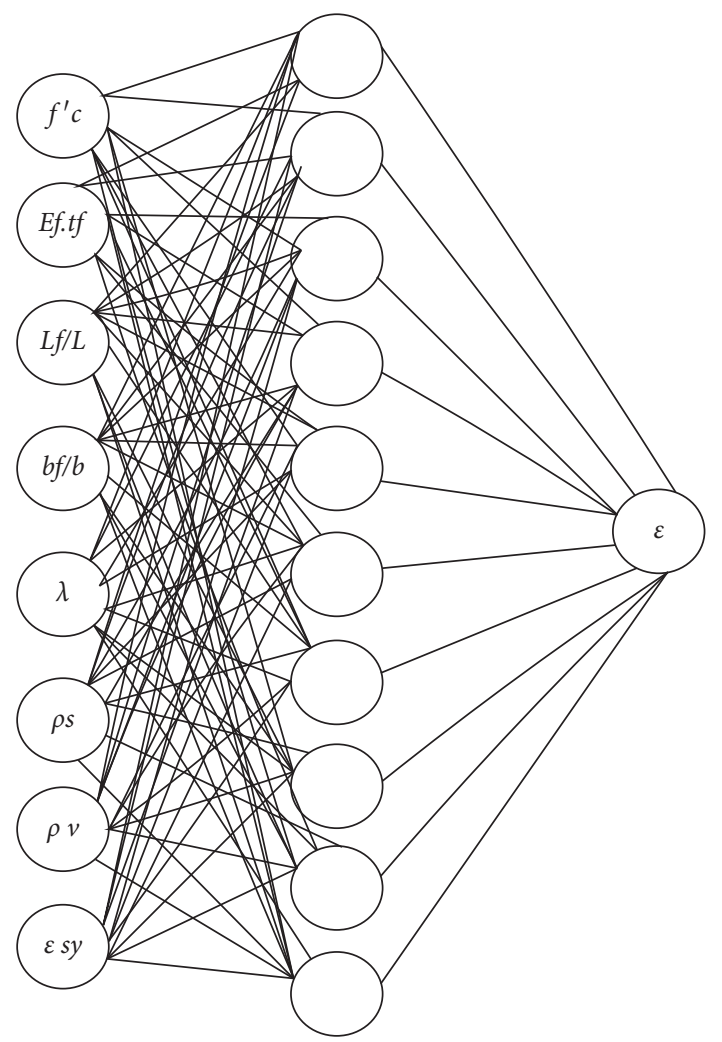

FIgUre 4: Topology of SSA-BP.

From Figure 10, it can be seen that $X_{1}, X_{5}$, and $X_{6}$, which are the concrete strength, shear-to-span ratio, and longitudinal reinforcement ratio, respectively, have a greater effect on the debonding strain; they can make the debonding strain of the strengthened beams increase. However, the FRP stiffness, $X_{2}$, is negatively correlated with the debonding strain, indicating that the increase of FRP stiffness will accelerate the debonding of the strengthened beams.

\section{Model Evaluation}

To further study the effectiveness of the SSA-BP model, the SSA-BP regression value was compared with several current international codes.

The ACI440.2R modified the maximum tensile strain of the FRP reinforcements of flexurally strengthened specimens with intermediate crack-induced debonding failure [7] and proposed the debonding strain limitation of FRPstrengthened RC beams:

$$
\varepsilon_{f d}=0.41 \sqrt{\frac{f_{c}^{\prime}}{n E_{f} t_{f}}} \leq 0 \cdot 9 \varepsilon_{f u},
$$

where $\varepsilon_{f d}$ is the debonding strain of FRP-strengthened RC beams; $f_{c}$ is the compressive strength of concrete; $n$ is the number of layers of FRP reinforcements; $E_{f}$ is the elastic modulus of FRP; $t_{f}$ is the thickness of the single layer of FRP; and $\varepsilon_{f u}$ is the ultimate tensile strain of FRP.

The JSCE [8], according to the model proposed by $\mathrm{Wu}$ [27], taking into account the degree of crack propagation after the debonding failure of the FRP and concrete interface, recommended that the debonding strain of FRPstrengthened RC beams is calculated as follows:

$$
\varepsilon_{f d} \leq \sqrt{\frac{2 G_{f}}{E_{f} t_{f}}},
$$

where $G_{f}$ is the fracture energy of the bonding interface between FRP and concrete; it should be determined by testing the strengthened members; and the value is generally taken as $0.5 \mathrm{~N} / \mathrm{mm}$.

The debonding strain of FRP-strengthened RC beams in the "Guidelines for the Design of Reinforced Concrete Structures with Fiber Composite Materials" [9] (TR55) issued by the Advisory Committee of Building Technical Regulations of the Italian National Research Council is calculated as follows: 

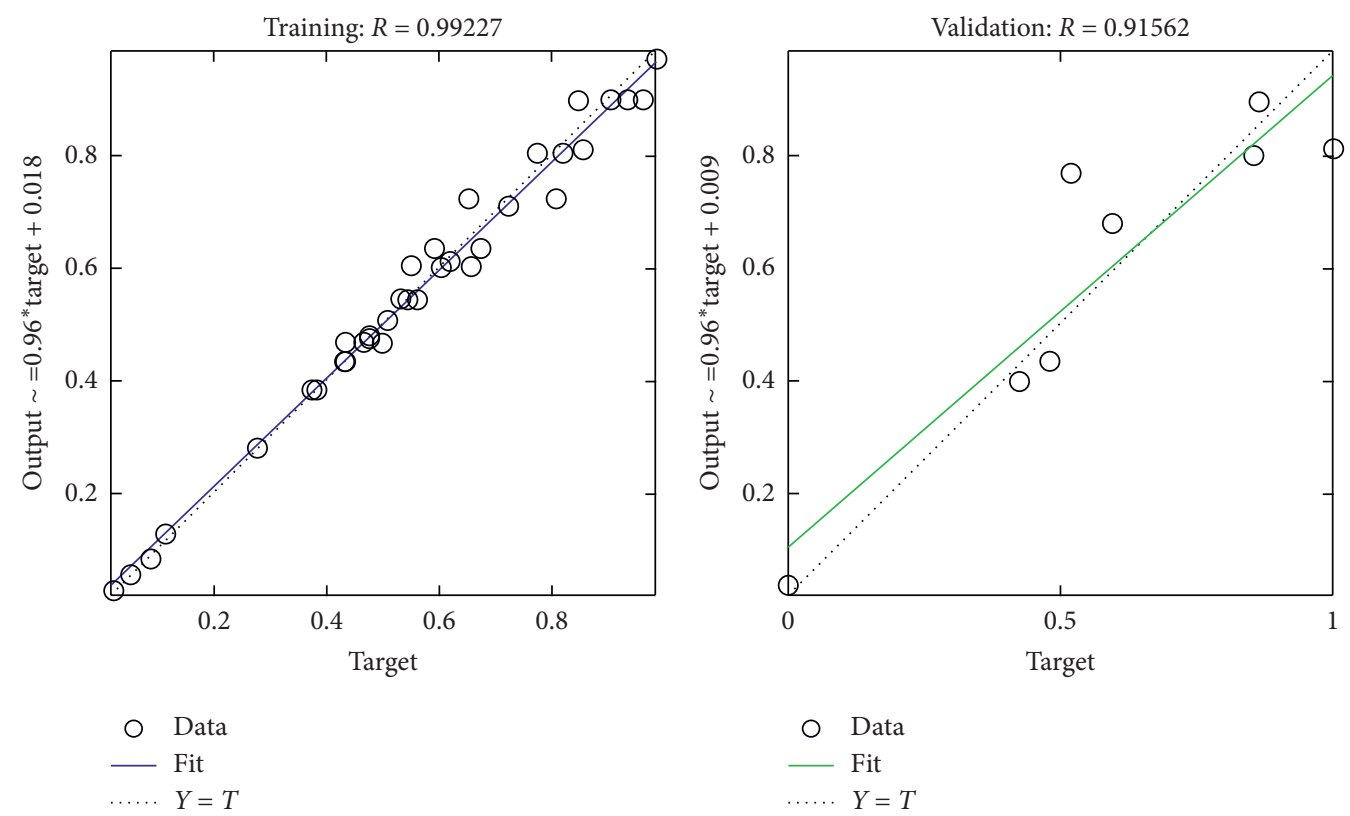

(a)
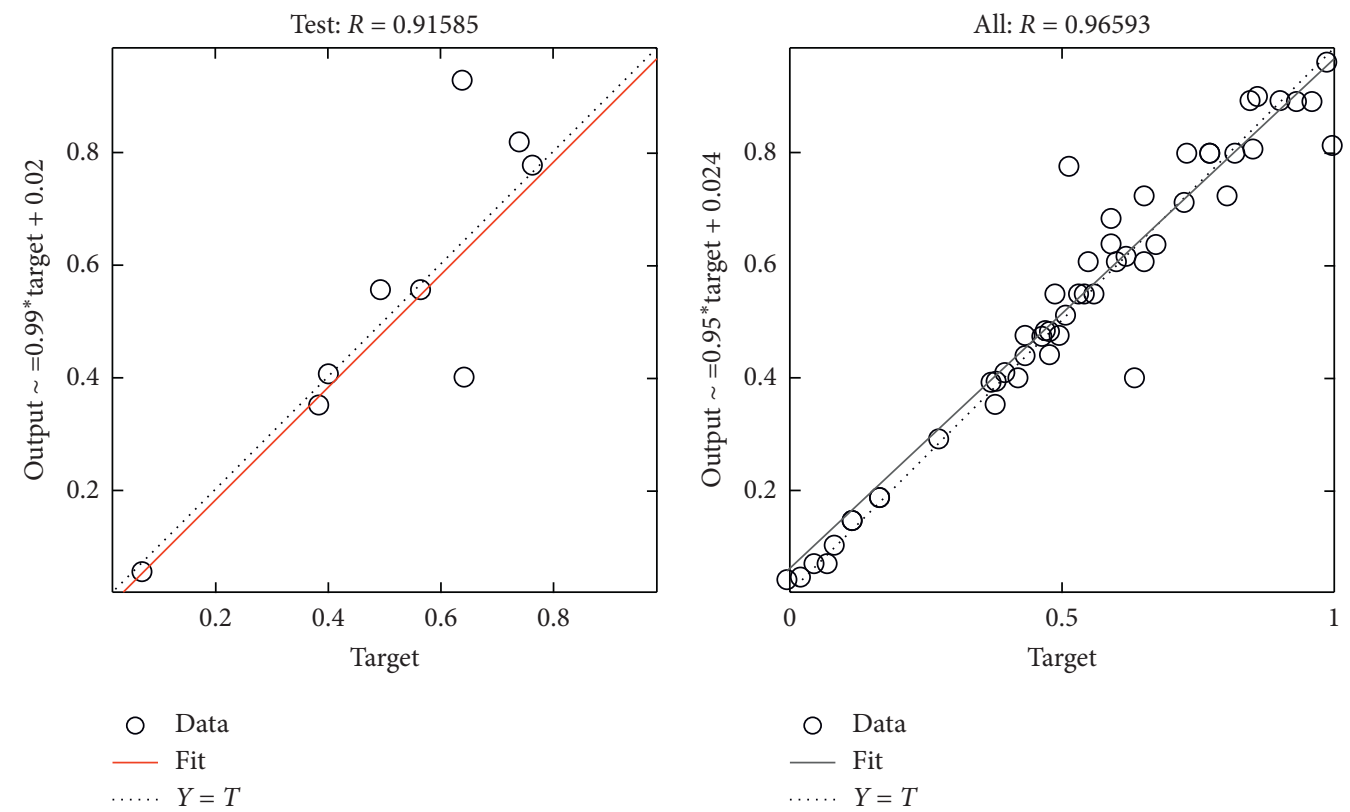

(b)

FIGURE 5: Simulation results of SSA-BP.

$$
\varepsilon_{f d}=0.484 \sqrt{\frac{k_{b} \sqrt{f_{c}^{\prime} f_{c t}}}{n E_{f} t_{f}}},
$$

where $k_{b}$ is the width coefficient of FRP reinforcements.

The formula for the debonding strain of FRPstrengthened RC beams recommended by the "Fiber Reinforced Materials Reinforced Concrete Structures" [10] (CNR) issued by the British Concrete Association is given in the following equation:

$$
\varepsilon f d=0.5 k b \sqrt{\frac{f_{c t}}{E_{f} t_{f}}},
$$

The calculated values by the code models and the predicted value by SSA-BP are shown in Figure 11.

It can be seen from Figure 11 that the model calculation value distribution proposed by the codes is relatively discrete, and SSA-BP is significantly better than JSCE, ACI, CNR, and TR55 in terms of model fit. In addition, Table 4 

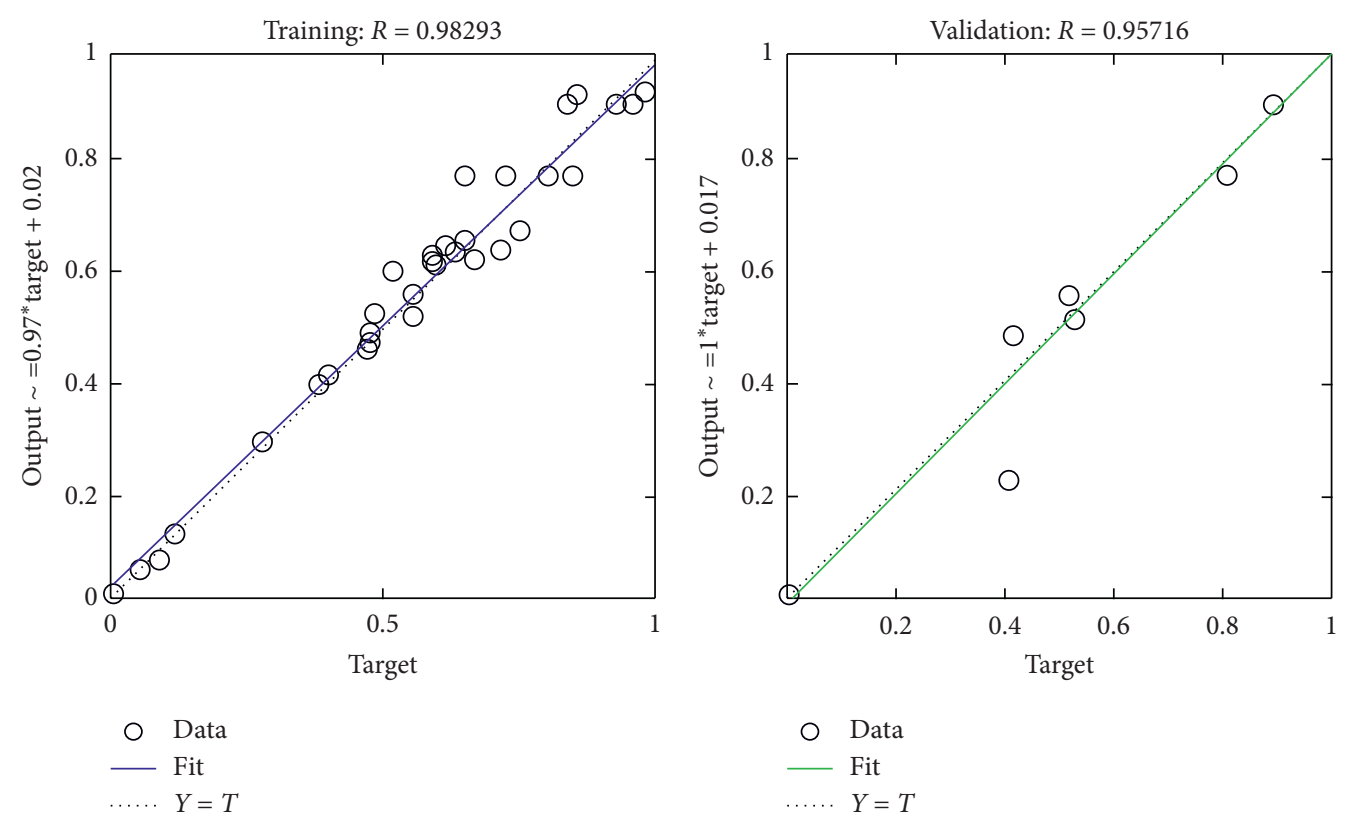

(a)
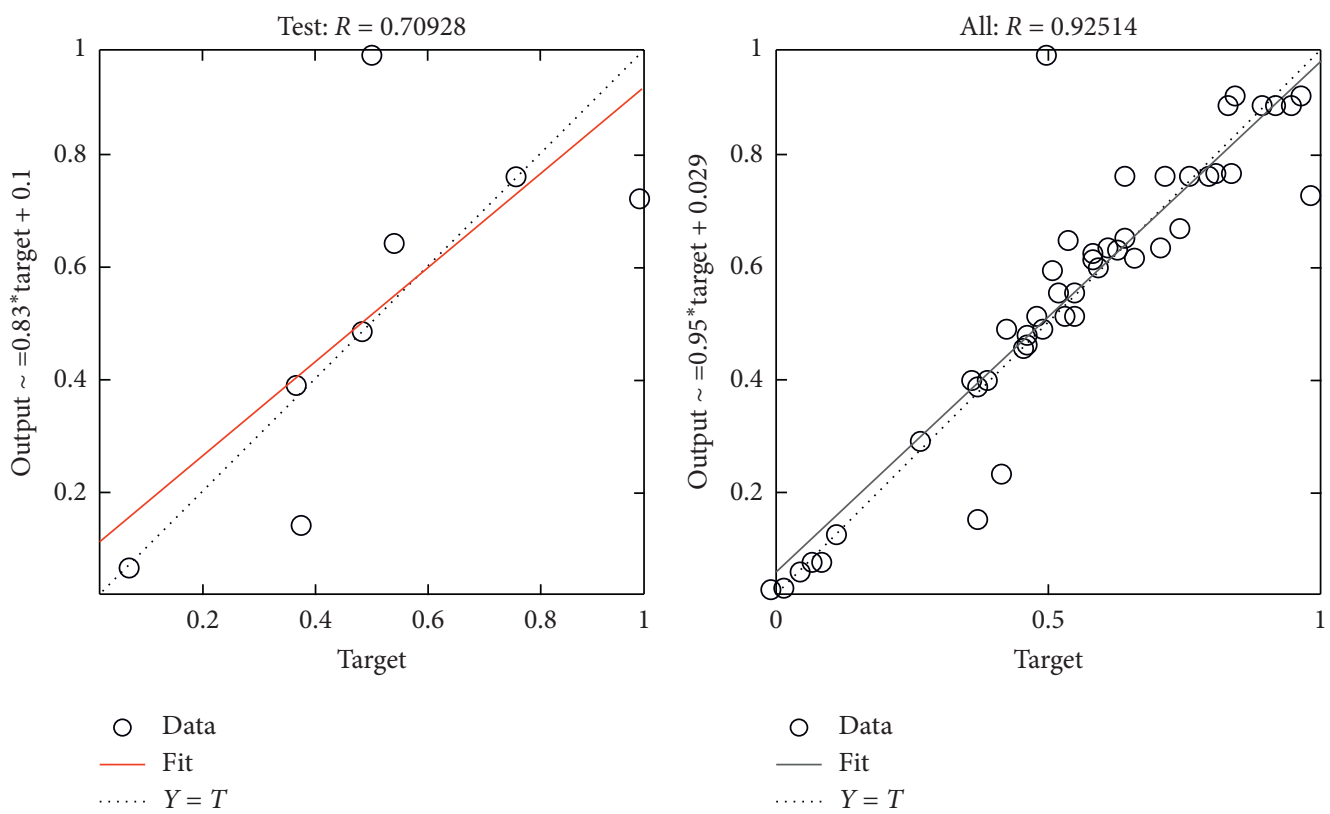

(b)

FIGURE 6: Simulation results of BP.

further analyzes the prediction accuracy and robustness of the model built in this study and national codes.

From Table 4, the model values of JSCE, ACI, CNR, TR55, and SSA-BP are 0.22-1.63, 0.50-4.24, 0.24-1.48, $0.20-1.42$, and $0.35-1.17$ times of the experimental value, respectively. The coefficient of variation of all the code models is greater than $45 \%$. However, the coefficient of variation of SSA-BP is only $13 \%$. Compared with the codes, SSA-BP has a smaller degree of dispersion. The JSCE, TR55, and CNR models are very conservative with an average less than 0.55 ; there are about $92 \%, 93 \%$, and $95 \%$ of all the specimens with the predicted value underestimated. The ACI model is significantly overestimated the debonding strain with an average of 1.39 , and about $68 \%$ of all the 


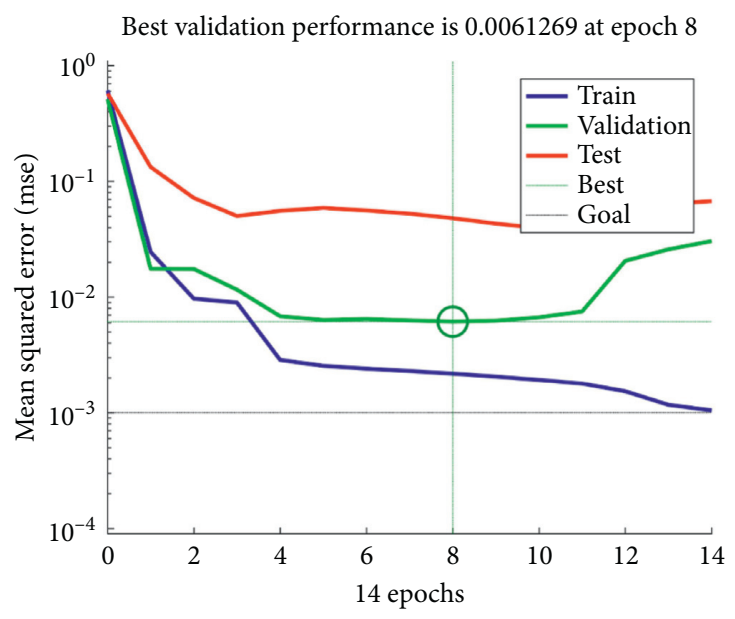

Figure 7: Performance of SSA-BP.

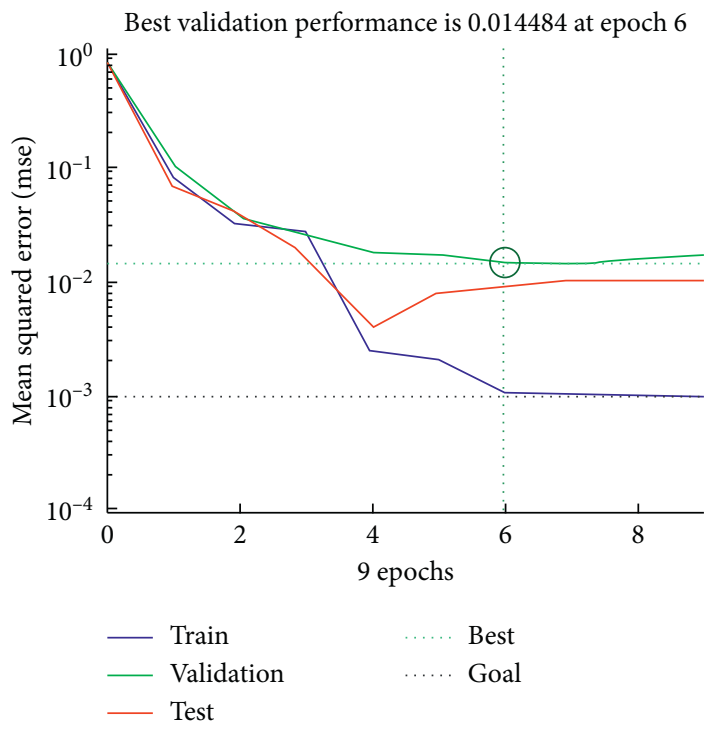

Figure 8: Performance of BP.

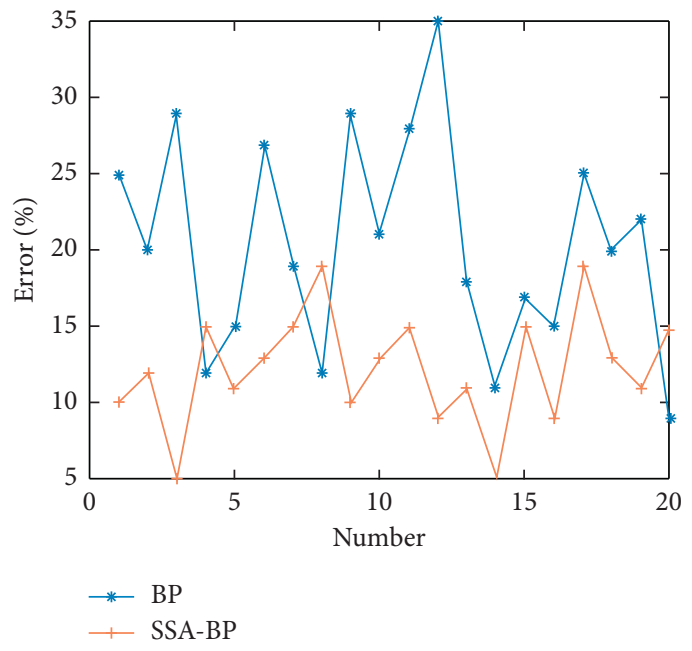

FIgURE 9: Error comparison of SSA-BP and BP. 
TABLE 2: Connection weights of the input layer and the hidden layer.

\begin{tabular}{lcccccccc}
\hline & $X_{1}$ & $X_{2}$ & $X_{3}$ & $X_{4}$ & $X_{5}$ & $X_{6}$ & $X_{7}$ \\
\hline$H_{1}$ & -0.39 & 0.20 & -0.53 & 0.34 & -0.46 & 0.62 & -0.37 & 0.44 \\
$H_{2}$ & 0.61 & -0.66 & 0.41 & -0.77 & 0.00 & -0.46 & -0.34 & -0.31 \\
$H_{3}$ & -0.57 & 0.49 & -0.19 & -1.37 & -0.70 & -1.04 & -0.88 \\
$H_{4}$ & -0.16 & -0.28 & 0.11 & 0.66 & 0.11 & 0.02 & -0.36 \\
$H_{5}$ & -0.52 & -0.58 & -0.01 & -0.63 & 0.19 & -0.68 & -0.08 & -0.37 \\
$H_{6}$ & 0.10 & -0.49 & 0.11 & -0.21 & -0.05 & 0.26 & 0.09 & -0.25 \\
$H_{7}$ & -0.60 & -0.67 & -1.33 & 0.59 & -0.24 & 0.02 & -0.92 \\
$H_{8}$ & -0.22 & -0.28 & 0.01 & 0.13 & 0.09 & -0.59 & -0.04 & -0.22 \\
$H_{9}$ & -0.35 & -0.13 & -0.01 & 0.03 & 0.52 & -0.18 & -0.55 & -0.02 \\
$H_{10}$ & 0.14 & 0.06 & -0.44 & 0.05 & 0.13 & 0.06 & -0.17 \\
\hline
\end{tabular}

TABLE 3: Connection weights of the hidden layer and the output layer.

\begin{tabular}{|c|c|c|c|c|c|c|c|c|c|c|}
\hline & $H_{1}$ & $\mathrm{H}_{2}$ & $\mathrm{H}_{3}$ & $\mathrm{H}_{4}$ & $\mathrm{H}_{5}$ & $H_{6}$ & $\mathrm{H}_{7}$ & $H_{8}$ & $H_{9}$ & $H_{10}$ \\
\hline$Y$ & -0.04 & 0.28 & -0.40 & -0.16 & 0.24 & -0.51 & 0.09 & -0.57 & 0.19 & -0.17 \\
\hline
\end{tabular}

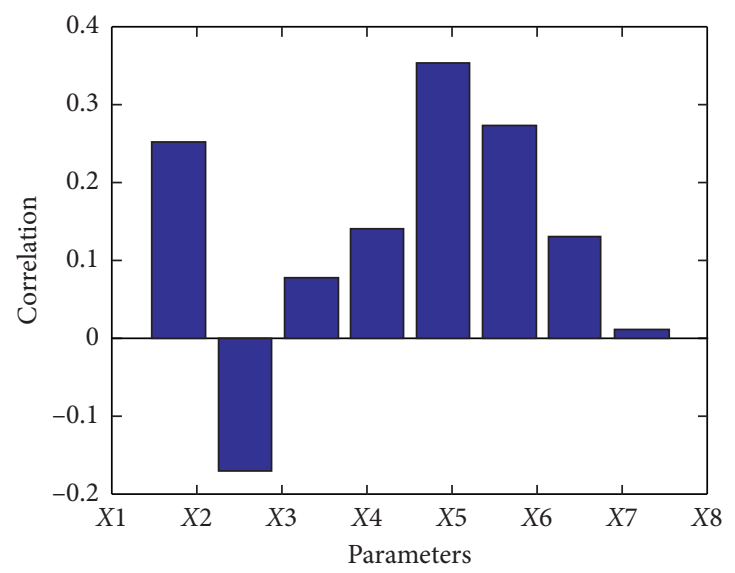

Figure 10: Effect of parameters on debonding strain.
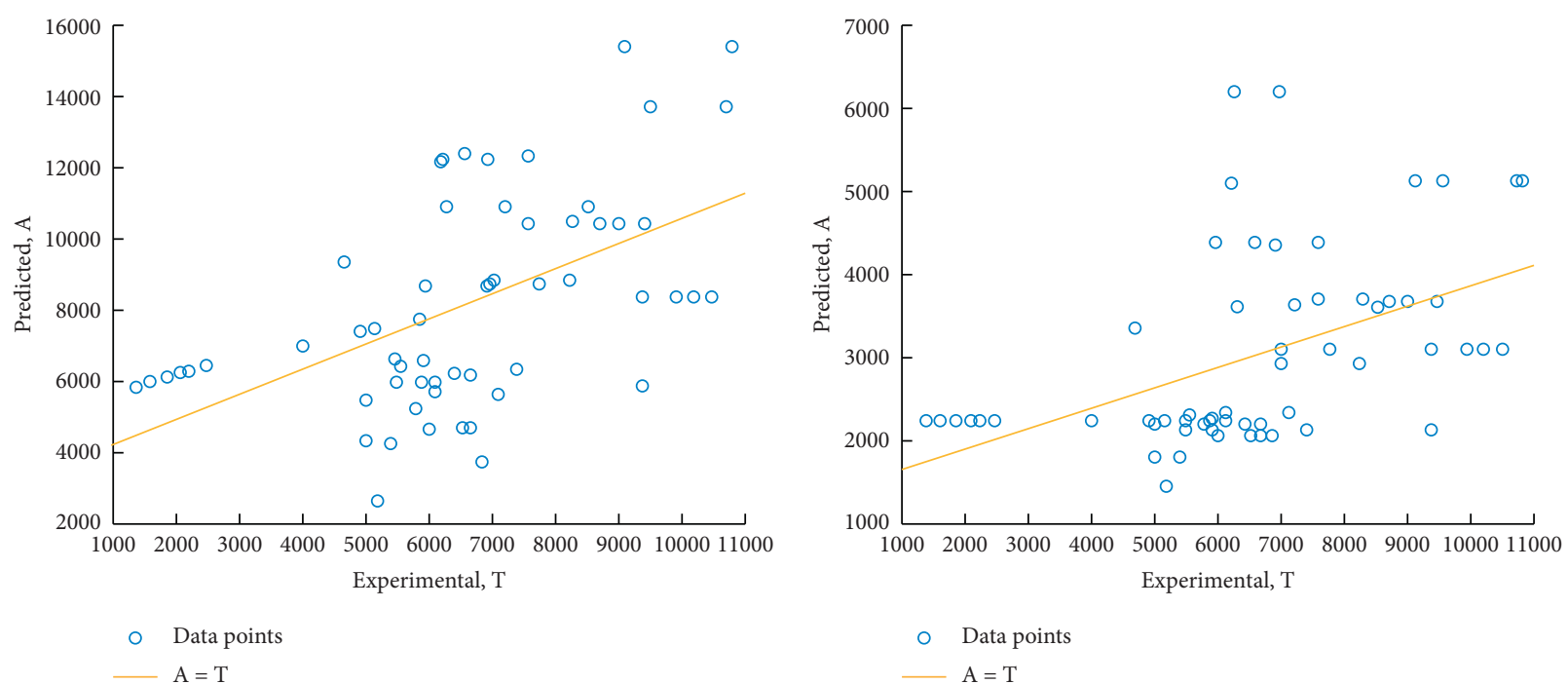

(a)

(b)

FIGURE 11: Continued. 


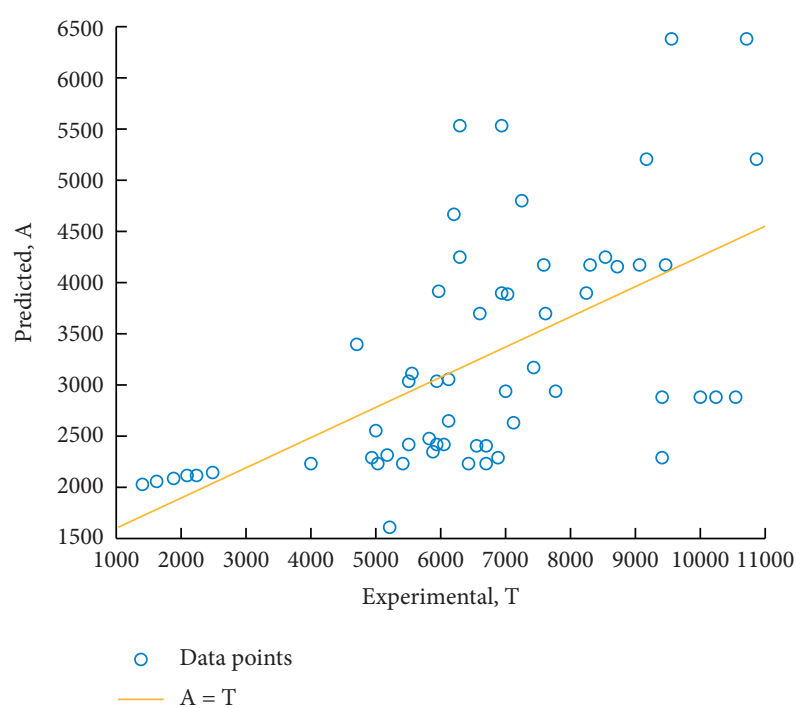

(c)

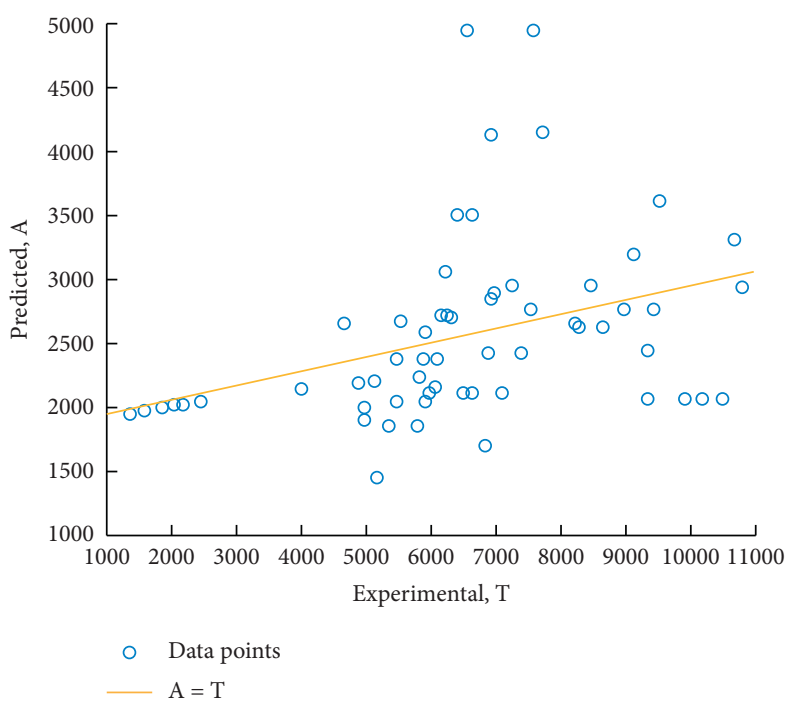

(d)

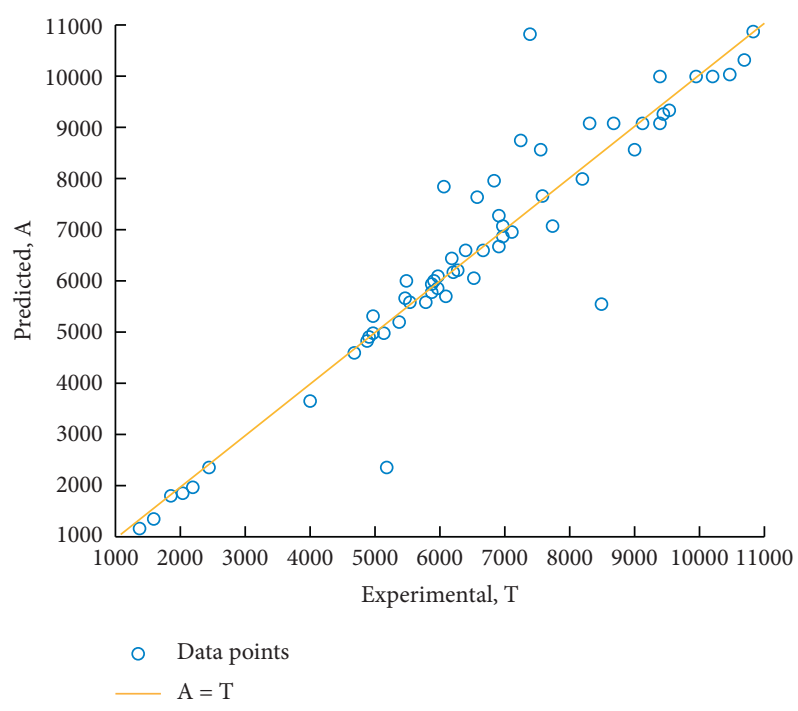

(e)

Figure 11: Predicted values and experimental values: (a) ACI, (b) JSCE, (c) TR55, (d) CNR, and (e) SSA-BP.

TABLE 4: Statistical results of each model.

\begin{tabular}{lccccc}
\hline & JSCE & ACI & CNR & TR55 & SSA-BP \\
\hline Min & 0.22 & 0.5 & 0.24 & 0.2 & 0.35 \\
Max & 1.63 & 4.24 & 1.48 & 1.42 & 1.17 \\
AV & 0.52 & 1.39 & 0.55 & 0.45 & 0.99 \\
STD & 0.29 & 0.75 & 0.24 & 0.24 & 0.13 \\
CV & $55 \%$ & $54 \%$ & $45 \%$ & $54 \%$ & $13 \%$ \\
C & $92 \%$ & $32 \%$ & $93 \%$ & $95 \%$ & $50 \%$ \\
N-C & $8 \%$ & $68 \%$ & $7 \%$ & $5 \%$ & $50 \%$ \\
\hline
\end{tabular}

specimens are overestimated. However, the conservative and nonconservative values calculated by the SSA-BP model account for $50 \%$; the SSA-BP is more stable than the codes.

\section{Conclusions}

(1) The SSA-BP model is better than the traditional BP neural network in terms of its accuracy and robustness. The concrete strength, shear-to-span ratio, and longitudinal reinforcement ratio have a great effect on the debonding strain of FRP-strengthened RC beams; the debonding strain of FRP-strengthened RC beams can be improved with the increase of them. The FRP stiffness is negatively correlated with the debonding strain; the debonding strain will be reduced with the increased FRP stiffness.

(2) The present model developed based on the SSA-BP neural network has a coefficient of variation of $13 \%$. 
Compared with JSCE, ACI, TR55, CNR, and other codes, it has higher accuracy and robustness.

(3) There are still some shortcomings in experimental data collection and model convergence speed. In the future, these two aspects need to be improved to establish a better prediction model of debonding strain of FRP-strengthened RC beam.

\section{Data Availability}

The data for the study were collected from articles by different researchers and have been marked in the article.

\section{Additional Points}

Research Highlights. The influence of different parameters on debonding strain of FRP-strengthened RC beams is comprehensively considered. The sparrow search algorithm has been used to optimize the weights and thresholds of the BP neural network and establish a more accurate prediction model.

\section{Conflicts of Interest}

The authors declare no conflicts of interest.

\section{Acknowledgments}

The authors are grateful for the financial support from the Shandong Provincial Natural Science Foundation (Project no. ZR2017MEE019).

\section{References}

[1] M. Z. Naser, R. A. Hawileh, and J. A. Abdalla, "Fiber-reinforced polymer composites in strengthening reinforced concrete structures: a critical review," Engineering Structures, vol. 198, Article ID 109542, 2019.

[2] N. A. Nuaimi, "Durability of reinforced concrete beams externally strengthened with CFR Plaminates under harsh climatic conditions," Journal of Composites for Construction, vol. 25, no. 2, Article ID 04021005, 2021.

[3] R. Abokwiek, T. E. Maadday, RC columns strengthened with NSM-CFRP strips and CFRP wraps under axial and uniaxial bending: experimental investigation and capacity models," Journal of Composites for Construction, vol. 25, no. 2, Article ID 04021009, 2021.

[4] K. Helal, S. Yehia, R. Hawileh, and J. Abdalla, "Performance of preloaded CFRP-strengthened fiber reinforced concrete beams," Composite Structures, vol. 244, Article ID 112262, 2020.

[5] N. Al Nuaimi, M. G. Sohail, R. A. Hawileh, J. A. Abdalla, and K. Douier, "Durability of reinforced concrete beams strengthened by galvanized steel mesh-epoxy systems under harsh environmental conditions," Composite Structures, vol. 249, Article ID 112547, 2020.

[6] H. A. Rasheed, J. Abdalla, R. Hawileh, and A. K. Al-Tamimi, "Flexural behavior of reinforced concrete beams strengthened with externally bonded aluminum alloy plates," Engineering Structures, vol. 147, pp. 473-485, 2017.
[7] ACI-440.2R, Guide for the Design and Construction of Externally Bonded FRP Systems for Strengthening Concrete Structures, ACI-440, Farmington Hills, MI, USA, 2017.

[8] Japan Society of Civil Engineers (JSCE), Recommendations for upgrading of concrete structures with use of continuous fiber sheets. Concrete Engineering Series, Japan Society of Civil Engineers, Nagaoka, Japan, 2001.

[9] Concrete Society, Design Guidance for Strengthening Concrete Structures using Fibre Composite Materials, Concrete Society, Crowthorne, UK, 2012.

[10] National Research Council, Guide for the design and construction of externally bonded FRP systems for strengthening existing structures (CNR-DT 200 R1), CNR, Rome, Italy, 2013.

[11] J.G. Teng, "Intermediate crack-induced debonding in RC beams and slabs," Construction and Building Materials, vol. 17, no. 6-7, pp. 447-462, 2003.

[12] Y. J. Kim and K. A. Harries, "Statistical characterization of reinforced concrete beams strengthened with FRP sheets," Journal of Composites for Construction, vol. 17, no. 3, pp. 357-370, 2013.

[13] E. Oller, D. Cobo, and A. R. Marí, "Laminate debonding process of FRP-strengthened beams," Structure and Infrastructure Engineering, vol. 7, no. 1-2, pp. 131-146, 2011.

[14] X. Z. Lu, J. G. Teng, L. P. Ye, and J. J. Jiang, "Intermediate crack debonding in FRP-strengthened RC beams: FE analysis and strength model," Journal of Composites for Construction, vol. 11, no. 2, pp. 161-174, 2007.

[15] A. Bilotta, F. Ceroni, E. Nigro, and M. Pecce, "Efficiency of CFRPNSM strips and EBR plates for flexural strengthening of RC beams and loading pattern influence," Composite Structures, vol. 124, pp. 163-175, 2015.

[16] P. Rusinowki and B. Täljsten, "Intermediate crack induced debonding in concrete beams strengthened with CFRP plates - an experimental study," Advances in Structural Engineering, vol. 12, no. 6, pp. 793-806, 2009.

[17] J. Y. Xu, B. B. Zheng, and G. B. Li, "Study on allowable peeling strain of reinforced concrete beams with externally bonded CFRP," China Safety Science Journal, vol. 28, no. 7, pp. 70-75, 2018.

[18] O. R. Abuodeh, J. A. Abdalla, and R. A. Hawileh, “Assessment of compressive strength of ultra-high performance concrete using deep machine learning techniques," Applied Soft Computing, vol. 95, 2020.

[19] P. Gao, Y. H. Zhao, L. Hong et al., "Effect of corner radius on axial compressive performance of steel reinforced concrete rectangular short columns confined by CFRP," ActaMateriaeCompositaeSinica, vol. 37, 2020.

[20] O. R. Abuodeh, J. A. Abdalla, and R. A. Hawileh, "Prediction of shear strength and behavior of RC beams strengthened with externally bonded FRP sheets using machine learning techniques," Composite Structures, vol. 234.

[21] F. Yu and X. Xu, "A short-term load forecasting model of natural gas based on optimized genetic algorithm and improved BP neural network," Applied Energy, vol. 134, pp. 102-113, 2014.

[22] T. Hu, IOP Conference Series Earth Environmental Science, vol. 719, Article ID 022028, 2021.

[23] G. Ayea, "Forecasting the Price of Gold Using Dynamic Model Averaging," International Review Of Financial Analysis, vol. 41, pp. 257-266, 2015.

[24] Y. Shi, R. M. Liu, Y. Luo, and K. Yang, "The temporal and spatial process of PM_(2.5) pollution evolution in China in the past 20 years," Environmental Science, vol. 41, no. 1, pp. 1-13, 2020. 
[25] J. K. Xue, Research and Application of a New Type of Swarm Intelligence Optimization Technology, Donghua University, Shanghai, China, 2020.

[26] Y. L. Li, S. Q. Wang, Q. R. Chen, and X. G. Wang, "Comparative study of several new swarm intelligence optimization algorithms," Computer Engineering and Applications, vol. 56, no. 22, pp. 1-12, 2020.

[27] $\mathrm{Z} . \mathrm{Wu}$ and H. Niu, "Prediction of crack-induced debonding failure in R/C structures flexurally strengthened with externally bonded FRP composites," Doboku Gakkai Ronbunshuu E, vol. 63, no. 4, pp. 620-639, 2007.

[28] R. Bakay, E. Y. Sayed-Ahmed, and N. G. Shrive, "Interfacial debonding failure for reinforced concrete beams strengthened with carbon-fibre-reinforced polymer strips," Canadian Journal of Civil Engineering, vol. 36, no. 1, pp. 103-121, 2009.

[29] H.B. Pham and R. Al-Mahaidi, "Assessment of available prediction models for the strength of FRP retrofitted RC beams," Composite Structures, vol. 66, no. 1-4, pp. 601-610, 2004.

[30] F. Ceroni, M. Pecce, S. Matthys, and L. Taerwe, "Debonding strength and anchorage devices for reinforced concrete elements strengthened with FRP sheets," Composites Part B: Engineering, vol. 39, no. 3, pp. 429-441, 2008.

[31] J. M. Sena-Cruz, J. A. O. Barros, M. R. F. Coelho, and L. F. F. T. Silva, "Efficiency of different techniques in flexural strengthening of RC beams under monotonic and fatigue loading," Construction and Building Materials, vol. 29, pp. 175-182, 2012.

[32] O. Gunes, O. Buyukozturk, and E. Karaca, "A fracture-based model for FRP debonding in strengthened beams," Engineering Fracture Mechanics, vol. 76, no. 12, pp. 1897-1909, 2009.

[33] G. Spadea, F. Bencardino, and R.N. Swamy, "Optimizing the performance characteristics of beams strengthened with bonded CFRP laminates," Materials and Structures, vol. 33, no. 226, pp. 119-126, 2000.

[34] J. Pan, C. K. Y. Leung, and M. Luo, "Effect of multiple secondary cracks on FRP debonding from the substrate of reinforced concrete beams," Construction and Building Materials, vol. 24, no. 12, pp. 2507-2516, 2010.

[35] T. W. White, K. A. Soudki, and M.-A. Erki, "Response of RC beams strengthened with CFRP laminates and subjected to a high rate of loading," Journal of Composites for Construction, vol. 5, no. 3, pp. 153-162, 2001.

[36] Y.-C. You, K.-S. Choi, and J. Kim, "An experimental investigation on flexural behavior of RC beams strengthened with prestressed CFRP strips using a durable anchorage system," Composites Part B: Engineering, vol. 43, no. 8, pp. 3026-3036, 2012.

[37] S. F. Brena, "Increasing flexural capacity of reinforced concrete beams using carbon fiber-reinforced polymer composites," $A C I$ Structural Journal, vol. 100, no. 1, pp. 36-46, 2003.

[38] A.-H. Zhang, W.-L. Jin, and G.-B. Li, "Behavior of preloaded RC beams strengthened with CFRP laminates," Journal of Zhejiang University-SCIENCE A, vol. 7, no. 3, pp. 436-444, 2006.

[39] R. Kotynia and S. Cholostiakow, "New proposal for flexural strengthening of reinforced concrete beams using CFRP T-shaped profiles," Polymers, vol. 7, no. 11, pp. 2461-2477, 2015.

[40] J. Aidoo, K. A. Harries, and M. F. Petrou, "Fatigue behavior of carbon fiber reinforced polymer-strengthened reinforced concrete bridge girders," Journal of Composites for Construction, vol. 8, no. 6, pp. 501-509, 2004.
[41] M. Ali-Ahmad, K. Subramaniam, and M. Ghosn, "Experimental investigation and fracture analysis of debonding between concrete and FRP sheets," Journal of Engineering Mechanics, vol. 132, no. 9, pp. 914-923, 2006.

[42] T.-K. Lee, A. D. E. Pan, and M. J. L. Ma, "Ductile design of reinforced concrete beams retrofitted with fiber reinforced polymer plates," Journal of Composites for Construction, vol. 8 , no. 6 , pp. 489-500, 2004. 